\title{
Comparative dosimetry in intracavitary balloon catheter brachytherapy with I-125 and in Cf-252 brachytherapy combined with BNCT for brain tumors*
}

\author{
Dosimetria comparativa da braquiterapia por balão de l-125 e por Cf-252 associada à BNCT para tumores \\ cerebrais
}

\author{
Sâmia de Freitas Brandão ${ }^{1}$, Tarcísio Passos Ribeiro de Campos ${ }^{2}$
}

\begin{abstract}
Objective: Comparative analysis of dosimetry in intracavitary balloon catheter brachytherapy with I-125 and in Cf-252 brachytherapy combined with BNCT for treatment of brain tumors. Materials and Methods: Simulations of intracavitary balloon catheter brachytherapy with I-125 and in Cf-252 brachytherapy combined with BNCT were performed with the MCNP5 code, modeling the treatment of a brain tumor on a voxel computational phantom representing a human head. Absorbed dose rates were converted into biologically weighted dose rates. Results: Intracavitary balloon catheter brachytherapy with $\mathrm{I}-125$ produced biologically weighted mean dose rates of 3.2E-11, 1.3E-10, 1.9E-11 and 6.9E-13 RBE.Gy. $h^{-1} \cdot p^{-1}$.s, respectively, on the healthy tissue, on the balloon periphery and on the $I_{1}$ and $I_{2}$ tumor infiltration zones. On the other hand, Cf-252 brachytherapy combined with BNCT produced a biologically weighted mean dose rate of 5.2E09, 2.3E-07, 8.7E-09 and 2.4E-09 RBE.Gy. $\mathrm{h}^{-1} \cdot \mathrm{p}^{-1} . \mathrm{s}$, respectively on the healthy tissue, on the target tumor and on the $I_{1}$ and $I_{2}$ infiltration zones. Conclusion: Cf-252 brachytherapy combined with BNCT delivered a selective irradiation to the target tumor and to infiltration zones, while intracavitary balloon catheter brachytherapy with I-125 delivered negligible doses on the tumor infiltration zones.
\end{abstract}

Keywords: Brachytherapy; Glioblastoma multiforme; Dosimetry; BNCT; MCNP.

Resumo Objetivo: Realização de uma análise dosimétrica comparativa entre a braquiterapia com balão preenchido com solução de I-125 e a braquiterapia por Cf-252 associada à BNCT, mediante simulação computacional de tratamento de tumor cerebral. Materiais e Métodos: Simulações da braquiterapia com balão preenchido com solução de l-125 e da braquiterapia por Cf-252 associada à BNCT foram elaboradas no código MCNP5, modelando o tratamento de tumores cerebrais em um fantoma computacional de cabeça humana em voxels. As taxas de dose absorvidas foram convertidas em taxas de dose ponderadas e apresentadas. Resultados: A braquiterapia com balão de $1-125$ apresentou taxa de dose ponderada média no tecido normal, na periferia do balão e nas infiltrações $I_{1}$ e $I_{2}$ de 3,2E-11, 1,3E-10, 1,9E-11 e 6,9E13 RBE.Gy. $h^{-1} \cdot \mathrm{p}^{-1} . \mathrm{s}$, respectivamente. Já a braquiterapia por Cf-252 associada à BNCT apresentou dose média no tecido normal, no tumor e nas infiltrações $I_{1}$ e $I_{2}$ de 5,2E-09, 2,3E-07, 8,7E-09 e 2,4E-09 RBE.Gy.h ${ }^{-1}$. $p^{-1}$.s, respectivamente. Conclusão: A braquiterapia por Cf-252 associada à BNCT produziu irradiação seletiva nas infiltrações e tumor, enquanto a braquiterapia com balão preenchido com solução de I-125 produziu doses negligenciáveis nas infiltrações. Unitermos: Braquiterapia; Glioblastoma multiforme; Dosimetria; BNCT; MCNP.

Brandão SF, Campos TPR. Comparative dosimetry in intracavitary balloon catheter brachytherapy with I-125 and in Cf-252 brachytherapy combined with BNCT for brain tumors. Radiol Bras. 2013 Jul/Ago;46(4):221-226.

* Study developed at Nuclear Engineering Department, Universidade Federal de Minas Gerais (UFMG), Belo Horizonte, MG, Brazil. Financial support: Coordenação de Aperfeiçoamento de Pessoal de Nível Superior (Capes).

1. Fellow PhD degree in Nuclear Sciences and Techniques, Nuclear Engineering Department, Universidade Federal de Minas Gerais (UFMG), Belo Horizonte, MG, Brazil.

2. PhD, Associate Professor, Universidade Federal de Minas Gerais (UFMG), Belo Horizonte, MG, Brazil.

Mailing Address: Sâmia de Freitas Brandão. Departamento de Engenharia Nuclear, Universidade Federal de Minas Gerais. Avenida Antônio Carlos, 6627, Campus UFMG, Escola de Engenharia, Bloco 4, Pampulha. Belo Horizonte, MG, Brazil, 31270 010. E-mail: samiabrandao@gmail.com.

Received December 6, 2012. Accepted after revision April 1st, 2013.

\section{INTRODUCTION}

Glioblastoma (GBM) is a malignant primary tumor, common among the central nervous system tumors, and is one of the two most deadly types of cancer because of its aggressiveness and ineffectiveness of treatments $^{(\mathbf{1}, \mathbf{2})}$. Generally, GBMs affect the brain hemispheres and, in some cases, may present with more than one area of growth ${ }^{(3)}$.

In cases of GBM, the anatomical location is a determining factor in the choice of the treatment, and tumor resection is the first option. However, the tumor resection is not always feasible due to the risk of causing even greater damage to brain functions. Additionally, as GBM is highly infiltrative, even with complete tumor resection, microscopic tumor extensions still remain in adjacent tissues, and cannot be removed ${ }^{(4)}$. The treatment purpose is, therefore, reducing the population of tumor cells, with ensuing radiotherapy and chemotherapy. Even so, recurrence is observed in most cases and the patient survival is generally no longer than two years ${ }^{(2)}$. 
Brachytherapy has been utilized in the treatment of primary brain tumors, particularly in cases of recurrence. Over the last years, a brachytherapy modality has been developed, consisting in a device comprising a balloon and a catheter for infusion of radioactive fluid. During the irradiation period, the balloon is filled with ${ }^{125}$ I radioactive solution, emitting photons with a mean energy of $28 \mathrm{keV}$, resulting in attenuation with fast dose decay ${ }^{(2,5)}$. The device is inserted into the patient during the surgical procedure for tumor resection, so the space originally occupied by the tumor is filled by the balloon ${ }^{(5,6)}$.

Another technique, still considered experimental and under continuous development over the past decades, is the boron neutron capture therapy (BNCT). Such a technique consists in intravenous administration of a boron compound to the patient, followed by irradiation with an epithermal neutron beam ${ }^{(7)}$. The boron contained in the compound captures neutrons in ${ }^{10} \mathrm{~B}(n, \alpha)^{7} \mathrm{Li}$ reactions, producing particles with high linear energy transfer and a mean range of 10 $\mu \mathrm{m}$ (approximately the cell diameter). Thus, the deposition of the dose resulting from the nuclear reaction with boron remains in the tumor. Additionally, as the cancer cells have a higher metabolism than healthy cells, the tumor absorbs a greater boron compound concentration of than the adjacent healthy tissue, thus promoting a selective irradiation effect ${ }^{(\mathbf{8})}$.

Brachytherapy with californium (Cf) needle may be employed as a neutrons source for BNCT. The ${ }^{252} \mathrm{Cf}$ is an isotope that suffers spontaneous fission, emitting fast neutrons with a mean energy of 2.1 $\mathrm{MeV}$, followed by gamma radiation. Its half-life is 2.7 years and it is considered as being satisfactory for utilization in brain tumors brachytherapy ${ }^{(9)}$.

The present study comprises a computer-simulated comparative dosimetric analysis between ${ }^{125} \mathrm{I}$ balloon brachytherapy and ${ }^{252} \mathrm{CF}$ brachytherapy associated with BNCT, considering GBM dissemination sites.

\section{MATERIALS AND METHODS}

The computer simulations were performed with the MCNP5 code, utilizing a human head voxel phantom ${ }^{(\mathbf{1 0})}$, built in the SISCODES program ${ }^{(\mathbf{1 1}, \mathbf{1 2})}$. In such a phantom, a hypothetical GBM was inserted, with dissemination in three regions which, in the present study, will be referred to as target tumor, infiltration $1\left(I_{1}\right)$ and infiltration $2\left(I_{2}\right)$. The target tumor and $I_{1}$ are located in the left temporal lobe with a volume of $13.7 \mathrm{~cm}^{3}$ and $0.43 \mathrm{~cm}^{3}$, respectively, while $I_{2}$ is located in the right temporal lobe, with a volume of $0.27 \mathrm{~cm}^{3}$.

First, a simulation of brachytherapy was performed with the balloon containing a solution of ${ }^{125} \mathrm{I}$. The SISCODES program was utilized to generate a file with all the information on the voxel phantom in a format compatible with MCNP5 code. The source was then defined as a sphere with 2 $\mathrm{cm}$ in diameter, with the center coinciding with the center of the target tumor, located at $4.3 \mathrm{~cm}$ from the skin, representing a partial resection of the tumor and the occupation of its original space by the balloon. The photons, with a mean energy of $28 \mathrm{keV}$, were uniformly emitted by all the volume of the sphere representing the source, and the code was utilized to calculate the energy deposition on the voxels of the phantom in MeV.g ${ }^{-1}$.

By means of a conversion factor, the code also converted the energy deposition $\left(\mathrm{MeV} \cdot \mathrm{g}^{-1}\right)$ into absorbed dose rate $\left(\mathrm{Gy} \cdot \mathrm{h}^{-1}\right.$. $\mathrm{p}^{-1}$.s), so that the absorbed dose could be better evaluated in terms of irradiation time. Such dose rate unit means that one gray (Gy) per hour (h) is deposited on the tissue when submitted to the fluence of one particle (p) emitted per second (s) by the source. In the present study, "p" means "particle", representing either photons or neutrons.

For the simulation of ${ }^{252} \mathrm{Cf}$ brachytherapy associated with BNCT, a boron concentration of $52.5 \mu \mathrm{g} . \mathrm{g}^{-1}$ was incorporated into the tumor and its infiltrations in the phantom, and $15 \mu \mathrm{g} . \mathrm{g}^{-1}$ into the adjacent healthy tissue (white matter, gray matter and limbic system). Such concentrations correspond to the uptake observed in clinical tests, as the boron compound is boronphenylalanine (BPA)-fructose) $)^{(\mathbf{1 3 , 1 4})}$.

Aiming at obtaining the absorbed dose with this technique, it was necessary to consider the neutron and gamma spectra emitted by the californium source, as well as the chemical composition of the human tissue and the reactions occurring due to the presence of boron in the tumor and its infiltrations as well as in the normal tissue. Thus, it could be concluded that the main components contributing to the total absorbed dose rate, in the BNCT $+{ }^{252} \mathrm{CF}$ combination, are the following:

- $D_{H}$ - dose by rapid neutrons - due to elastic interactions of the rapid neutrons emitted by the source with hydrogen, ${ }^{1} \mathrm{H}(n, n){ }^{1} \mathrm{H}$;

- $D_{S}$ - dose by gamma radiation from the source - due to the gamma radiation emitted by the ${ }^{252} \mathrm{Cf}$ source;

- $D_{\gamma}$ - dose by radioactive capture - due to thermal neutrons capture by hydrogen, ${ }^{1} \mathrm{H}(n, \gamma)^{2} \mathrm{H}$;

- $D_{N}$ - dose by thermal neutrons - due to thermal neutrons capture by nitrogen, ${ }^{14} \mathrm{~N}(n, p){ }^{14} \mathrm{C}$;

- $D_{B}$ - dose by boron - due to thermal neutrons capture by boron, ${ }^{10} \mathrm{~B}(n, \alpha){ }^{7} \mathrm{Li}$; Four separate cases were then run by the MCNP5 code, obtaining the energy deposition due to neutrons from the source $\left(D_{H}\right)$; the energy deposition due to gamma rays from the source $\left(D_{S}\right)$; the energy deposition due to radioactive capture $\left(D_{\gamma}\right)$ and the neutrons fluence in the voxels of the phantom.

The objective of running this latter case was obtaining the data for the calculation of the dose components by thermal neutrons $\left(D_{N}\right)$ and boron $\left(D_{B}\right)$, as the MCNP5 code version utilized in the simulations does not evaluate the transport of emitted secondary particles, such as protons, alpha particles and recoil nuclei. With the neutrons fluence and nitrogen and boron concentration in the tissues, it was possible to determine the ${ }^{14} \mathrm{~N}(n, p){ }^{14} \mathrm{C}$ and ${ }^{10} \mathrm{~B}(n, \alpha){ }^{7} \mathrm{Li}$ reaction rates and, considering the energies released in such reactions and the voxel mass, the energy deposited in the voxels of the phantom was found. Such energy was converted into absorbed dose rate $\left(\mathrm{Gy} \cdot \mathrm{h}^{-1}\right.$. $\mathrm{p}^{-1}$.s) by means of the same previously mentioned conversion factor.

In the simulations to obtain the $D_{H}, D_{\gamma}$ and the neutrons fluence components, the ${ }^{252} \mathrm{Cf}$ source was defined as a cylinder with $7.6 \mathrm{~mm}$ in length and $0.7 \mathrm{~mm}$ in diameter, encapsulated by $0.2 \mathrm{~mm}$ thick stainless steel. The adopted positioning was the center of the target tumor, at $4.3 \mathrm{~mm}$ from the skin. 
The neutrons were uniformly emitted by the entire cylinder volume which represents the active nucleus of the source. The energy spectrum of the emitted neutrons was represented by the Watt's function, with mean energy of $2.1 \mathrm{MeV}$. The utilization of the Watt's spectrum is recommended by the MCNP5 code to represent the neutrons from spontaneous ${ }^{252} \mathrm{Cf}$ fission ${ }^{(15)}$. In the simulation to obtain the $D_{S}$ component, the photons emission by the californium source was considered to obtain the absorbed dose due to gamma rays from the source.

In the three cases performed to obtain the energy deposition in the voxels of the phantom, the code also converted such deposition into absorbed dose rate ( $\mathrm{Gy}$. $\left.\mathrm{h}^{-1} \cdot \mathrm{p}^{-1} \cdot \mathrm{s}\right)$, by means of the same conversion factor. Thus all absorbed dose rate components were determined.

In order to consider the biological effects from the radiation, the absorbed dose rate $\left(G y \cdot h^{-1}\right)$ for each component was multiplied by a weighting factor and, thus, the weighted dose rate was obtained (RBE.Gy.h ${ }^{-1}$ ). Such weighting factor takes into consideration the biological effects on the tissues due to a mixed radiation beam of high and low linear energy transfer (LET), in the present study represented by neutrons, $\alpha$ particles and gamma rays. The weighting factors adopted for neutrons and photons were 3.2 and 1 respectively, while in the boron containing tissue, a factor of 1.3 was adopted in the healthy tissue and a factor of 3.8 was adopted in the tumor and its infiltrations. In the case of ${ }^{125} \mathrm{I}$ balloon brachytherapy, the weighting factor was $1^{(\mathbf{1 3}, 14)}$.

The total weighted dose rate $\left(D_{w}\right)$ was obtained by the sum of the components of absorbed dose rate multiplied by their respective weighting factors.

\section{RESULTS}

The dosimetric analysis was performed considering the deposition of mean dose in the voxels of the tumor, the periphery of the balloon, the adjacent healthy tissue at each one of the tumor regions and of the healthy tissue as a whole, represented by all voxels filled by healthy tissue in the phantom. The voxels evaluated in the present study are under an axis parallel to the axial plane, as shown on Figure 1.

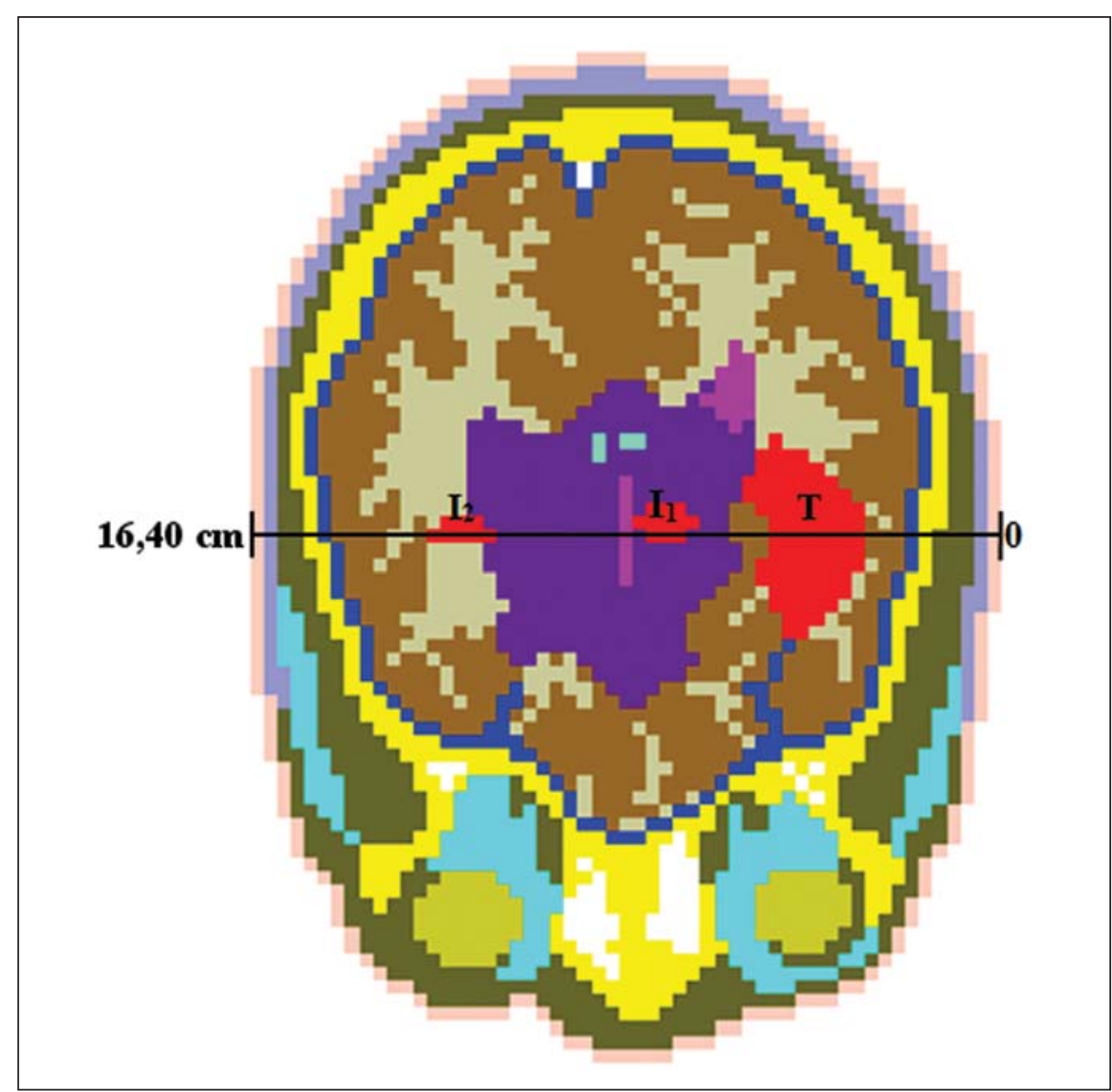

Figure 1. Axial plane on the computational model. The axis on the evaluated voxels crosses the center of the target tumor $(\mathrm{T})$ and also the infiltrations $\left(I_{1}\right.$ and $\left.I_{2}\right)$.

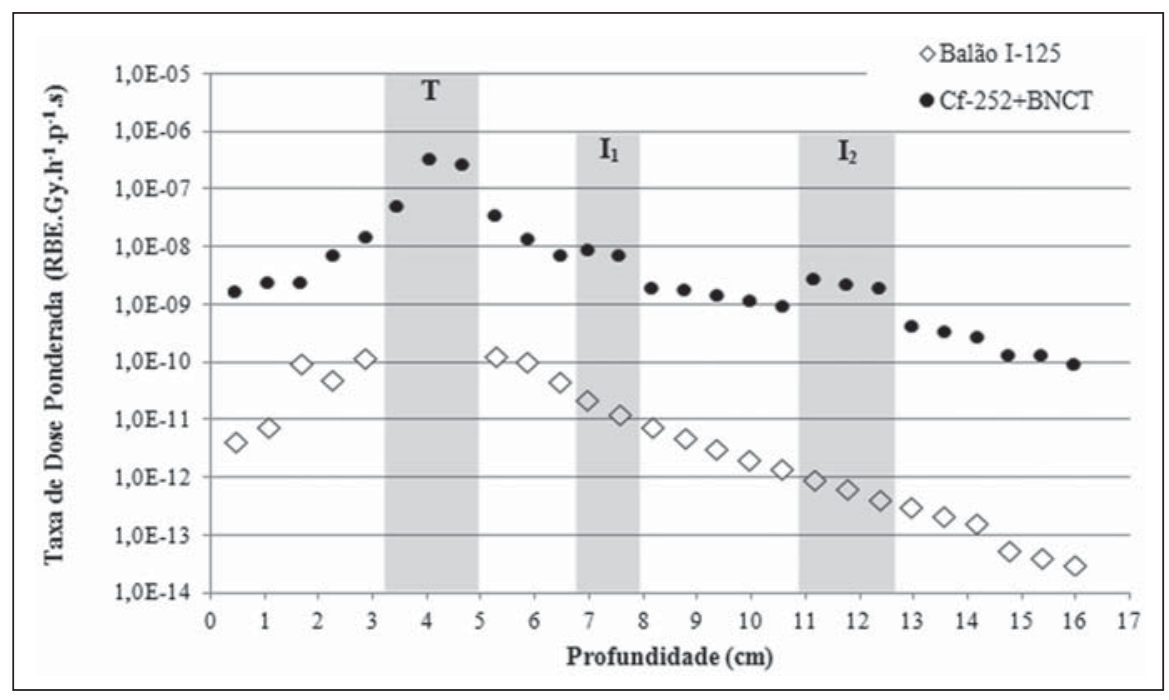

Figure 2. Weighted dose rates produced by ${ }^{125} \mathrm{I}$ brachytherapy and in ${ }^{252} \mathrm{Cf}$ brachytherapy associated with BNCT. The gray-shaded columns highlight the region of the target tumor $(\mathrm{T})$ and of the infiltrations $\left(I_{1}\right.$ and $\left.I_{2}\right)$.

Figure 2 presents the weighted dose rate produced by ${ }^{125} \mathrm{I}$ brachytherapy and by ${ }^{252} \mathrm{Cf}$ brachytherapy associated with BNCT.

The profile of the weighted dose rate produced at brachytherapy by ${ }^{125} \mathrm{I}$ filled bal- loon, shown on Figure 2, does not present dose deposition in the region of the target tumor because of its hypothetical resection, where the space left was filled by the balloon with the radioactive solution. The 
mean weighted dose rate in the healthy tissue (NTD) was 3.2E-11 RBE.Gy.h ${ }^{-1} \cdot \mathrm{p}^{-1} . \mathrm{s}$, while in the $I_{1}$ and $I_{2}$ infiltrations the mean dose rate was only 1.9E-11 (59\% DTN) and 6.9E-13 RBE.Gy.h ${ }^{-1} \cdot \mathrm{p}^{-1}$.s (2\% NTD), respectively. Such results demonstrate that there was neither deposited dose specificity in the tumor nor in the infiltrations. Additionally, the $I_{2}$ infiltration received a much lower mean dose than that in the adjacent healthy tissue, probably not resulting in a favorable clinical outcome.

On the other hand, the weighted dose rate profile produced by ${ }^{252} \mathrm{Cf}$ in association with BNCT, also shown on Figure 2, presents selectivity in the dose deposition on the tumor regions. The mean weighted dose rate in the entire healthy tissue was 5.2E09 RBE.Gy. $h^{-1} \cdot \mathrm{p}^{-1} . \mathrm{s}$, while in the tumor regions, i.e., tumor, $I_{1}$ and $I_{2}$, it was $9.0 \mathrm{E}-$ 08 RBE.Gy.h ${ }^{-1} \cdot \mathrm{p}^{-1}$.s. The ${ }^{252} \mathrm{Cf}$ brachytherapy presented a difference of two orders of brachytherapy, in dose deposition per particle emitted by the source in the time unit.

Figure 3 shows, in detail, the distribution of the weighted dose rate produced by the various components contributing to dose deposition in ${ }^{252} \mathrm{Cf}$ brachytherapy associated with BNCT.

As Figure 3 is analyzed, it is possible to notice that the highest dose deposition occurred in the tumor that received a mean magnitude, as compared with balloon

dose 21 times greater than the adjacent healthy tissue. As expected, due to the positioning of the californium source, the main contribution to the dose was from the component corresponding to the interaction of neutrons with the hydrogen present in the brain $\left(D_{H}\right)-91 \%$ of the total weighted dose.

The dose by boron $\left(D_{B}\right)$ component was responsible for the selectivity in dose deposition occurred in the infiltrations, contributing with $56 \%$ and $75 \%$ of the total dose, with dose deposition 13.4 and 9.5 times greater in the adjacent boron containing tissue, in the $I_{1}$ and $I_{2}$ infiltrations, respectively. In the first $2 \mathrm{~cm}$ of depth (voxels representing connective tissue, skeletal muscle and skull bone), as well as at a depth of $8 \mathrm{~cm}$ (ventricle) and after $14.5 \mathrm{~cm}$ (meninges, skeletal muscle and connective tissue), the $D_{B}$ component is null, as the boron concentration in those tissues was not defined. As previously mentioned, the boron concentration in the healthy tissue was only considered in the white matter, gray matter and limbic system.

\section{DISCUSSION}

GBMs present a high malignancy degree, tending to spread quickly, invading the healthy brain tissue. Studies and new technologies have been continuously de-

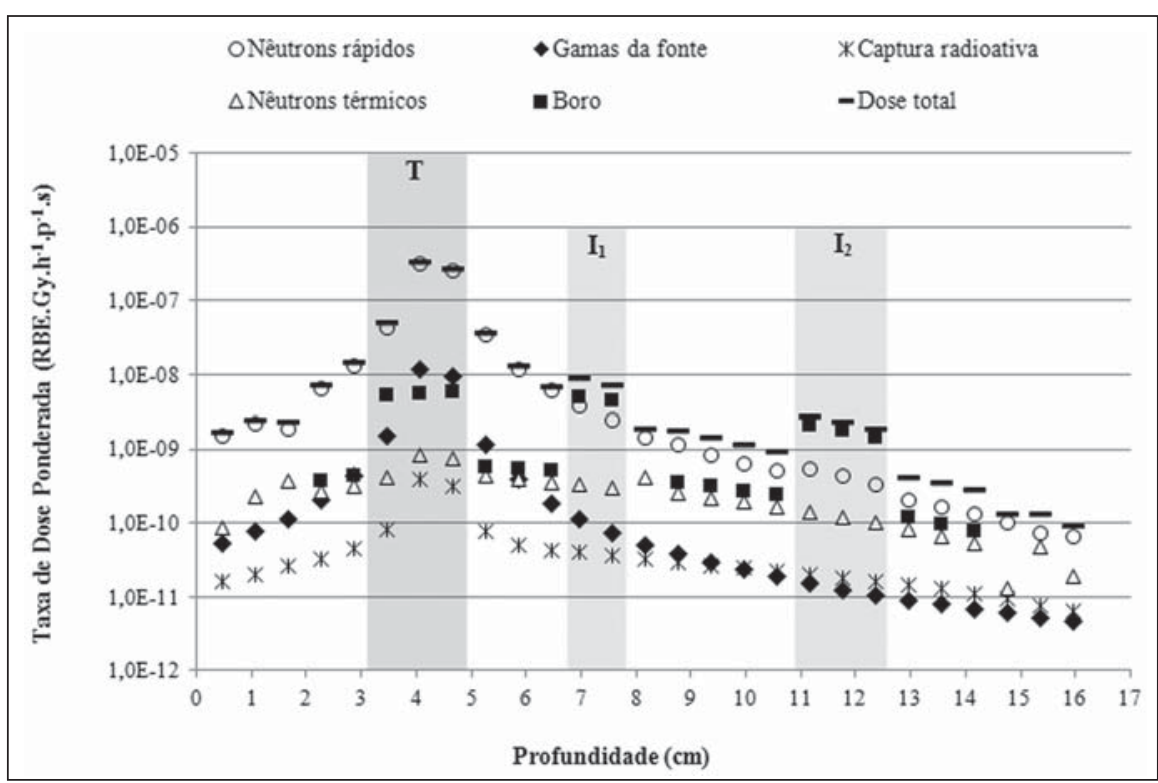

Figure 3. Total weighted dose rate $\left(D_{w}\right)$ and components of weighted dose rate $\left(D_{H}, D_{S}, D_{?}, D_{N}\right.$ and $\left.D_{B}\right)$ produced in ${ }^{252} \mathrm{Cf}$ brachytherapy associated with BNCT. The gray-shaded columns highlight the region of the target tumor $(\mathrm{T})$ and of the infiltrations $\left(I_{1} \mathrm{e} I_{2}\right)$. veloped with the purpose of maximizing tumor control while minimizing their side effects $^{(\mathbf{6 , 7 , 1 6 - 1 9 )}}$. However, the cure for GBM still represents a challenge understood as finding a way to resolve the elimination of cell residues and infiltrations in the periphery of the resected region. Currently, the standard protocol for newly-diagnosed GBMs comprises tumor resection, followed by radiotherapy with concomitant or adjuvant chemotherapy with mainly the chemotherapy agent temozolomide (TMZ). Even so, recurrence is observed in most of cases $^{(2,3)}$.

Brachytherapy has been proposed in cases of recurrence, but Schwarz et al. mention in their study several cases where ${ }^{125}$ I was utilized in the treatment of primary tumors $^{(20)}$. Intracavitary balloon catheter brachytherapy with ${ }^{125} \mathrm{I}$ has also presented encouraging results according to Liu et al. ${ }^{(21)}$, Niyazi et al. ${ }^{(22)}$ and Amelio et al. ${ }^{(2)}$. Studies reported by Wernicke et al. ${ }^{(23)}$ and, most recently, developed by Gobitti et al. ${ }^{(5)}$ show that the mean survival of patients treated with such a technique was 4.6-14 months and 13.7 months, respectively.

As regards BNCT, taking the boron to the tumor is still one of the challenges for the success of the technique. Currently, the only compounds in clinical use are BPA and BSH (boroncaptate sodium), but none of them is considered ideal in relation to their uptake by the tumor and tumor concentration:healthy tissue ratio ${ }^{(\mathbf{8 , 2 4 , 2 5})}$. As a result, several recent studies were aimed at the incorporation of boron into target tumor molecules by means of pepitides, proteins, antibodies, nucleosides, sugars, porfirines liposomes and nanoparticles, with promissing results in animal models and in vitro assays ${ }^{(\mathbf{8})}$. Besides taking the boron to the tumor, another difficulty in the utilization of BNCT is related to the neutrons required to the tumor irradiation. Generally, such neutrons are produced by nuclear reactors requiring complex premises, so the treatment becomes too expensive. However reports on treated cases with satisfactory results have been continuously published over the past two decades ${ }^{(\mathbf{7 , 2 6 - 2 8})}$.

Clinical results presented by Barth et al. demonstrate a mean survival of 7 to 21.9 months for a total of 190 GBM patients treated with BNCT between the years of 
1994 and 2008. Among 53 of such patients, only $9.4 \%$ reached a survival of two years ${ }^{(\mathbf{8})}$. Recently, the treatment of 23 patients with BNCT was reported in the study published by Kageji et al., where the mean survival was 19.5 months; and $26.1 \%$, $17.4 \%$ and $5.8 \%$ of the patients had a survival of two years, three years and five years, respectively. The authors also suggest that the combination of the technique with TMZ would produce better results ${ }^{(29)}$.

The association of BNCT with other radiotherapy techniques is also being evaluated. Studies where such technique was combined with irradiation by $\mathrm{x}$-rays, and adjuvant chemotherapy with TMZ have presented promissing results and will remain under study, according to Yamamoto et al. ${ }^{(27)}$ and Nakai et al. ${ }^{(28)}$. Another clinical trial which will continue, comprises the treatment of recurrent GBM with BNCT, as such technique has demonstrated to be safe and effective in management of the tumor, according to Aiyama et al. ${ }^{(26)}$.

The several BNCT protocols which have been developed (combination of boron compounds and association with other techniques), as well as other radiotherapy techniques, are aimed at benefiting the patients, by increasing their survival, or even controlling the tumor and improving their quality of life both during and after treatment. The results presented in the present study, for example, demonstrate that there is a significant difference between the presented techniques with respect to the treatment duration. In order to reach a boost of $20 \mathrm{~Gy}$ in the periphery of the tumor, ${ }^{125} \mathrm{I}$ brachytherapy with an activity of $0.5 \mathrm{Ci}$ $\left(1.85 \times 10^{10} \mathrm{~Bq}\right)$, must be utilized for 7.77 hours, while the same dose could be obtained by $50 \mu \mathrm{g}$ of ${ }^{252} \mathrm{Cf}$, with surgence of $1.15 \times 10^{8} \mathrm{n} . \mathrm{s}^{-1}$, in a period of 4.54 hours. Therefore, brachytherapy might be an option for the treatment of patients with recurrent or inoperable brain tumors. The choice between the techniques discussed in the present study depends, among other factors, on the tumor location and on the desired dose rate, which is directly related to the source's activity.

On Figure 2, it is possible to observe that ${ }^{125} \mathrm{I}$ brachytherapy presented an increase of the dose deposition in the bone, in the interval between 1 and $2 \mathrm{~cm}$ depths. Such increase in the dose is caused by the photoelectric effect produced by the interactions between the $28 \mathrm{keV}$ photons and bone component elements (particularly calcium and phosphorus) which are superior to the interactions in the brain in general. As the two dosimetries are compared, ${ }^{252} \mathrm{Cf}$ brachytherapy associated with BNCT presented a greater dose deposition in relation to balloon brachytherapy, which is due to the fact that interactions in ${ }^{252} \mathrm{Cf}$ brachytherapy are of a nuclear order (nuclear reactions), while at ${ }^{125} \mathrm{I}$ brachytherapy, the interactions are of an electronic order. Additionally, the boron compound employed at ${ }^{252} \mathrm{Cf}$ brachytherapy was responsible by the selectivity in the dose deposition observed in the infiltrations. Such a fact is explained by the high boron cross section (3840 b) for neutrons with thermal energy, as well as the $1 / \sqrt{ } E$ behavior of the cross section, where $E$ is the neutron kinetic energy. As they travel deeper in the tissue, the neutrons are moderated by the hydrogen present in human tissue, thus making such particles reach the infiltrations with lower energies, thermalized for the energy range where the cross section is higher. As they are captured by the boron, they promote a greater dose deposition in situ, by means of ${ }^{10} \mathrm{~B}(n, \alpha){ }^{7} \mathrm{Li}$ reactions.

Considering the highly infiltrative character of GBMs, ${ }^{252} \mathrm{Cf}$ brachytherapy associated with BNCT presents the advantage of providing a selective irradiation of the tumor cells. Even not being possible to visualize small infiltrations at diagnostic studies, or in those cases where the tumor is concentrated in more than one region of the brain, or even in cases where remnants of infiltrations remain after resection of the tumor, these are capable of uptaking the boron compound in greater concentration. Additionally, the ${ }^{252} \mathrm{Cf}$ source has a low cost and its association with BNCT may represent an alternative for the viabilization of such technique in radiotherapy centers.

\section{CONCLUSION}

The association of ${ }^{252} \mathrm{Cf}$ brachytherapy with BNCT demonstrated to be superior to balloon brachytherapy with ${ }^{125} \mathrm{I}$, as it was capable of producing differentiated irradiation on the infiltrations. In spite of the bo- ron compound not contributing significantly with dose deposition on the target tumor as compared with the scattering reactions with hydrogen, its uptake by the infiltrations provided a higher dose contribution than that of the neutrons emitted by the source, also sparing the adjacent healthy tissue.

\section{REFERENCES}

1. Haar CP, Hebbar P, Wallace GC 4th, et al. Drug resistance in glioblastoma: a mini review. Neurochem Res. 2012;37:1192-200.

2. Amelio D, Amichetti M. Radiation therapy for the treatment of recurrent glioblastoma: an overview. Cancers. 2012;4:257-80.

3. Ferreira NF, Barbosa M, Amaral LLF, et al. Estudo através da ressonância magnética de 67 casos de glioblastoma multiforme e a ocorrência de metástases. Arq Neuropsiquiatr. 2004;62:695700 .

4. Thumma SR, Elaimy AL, Daines N, et al. Longterm survival after gamma knife radiosurgery in a case of recurrent glioblastoma multiforme: a case report and review of the literature. Case Reports in Medicine [internet]. 2012 [cited 2012 Jun 21]. Available from: http://www.hindawi. com/crim/medicine/2012/545492/.

5. Gobitti C, Borsatti E, Arcicasa M, et al. Treatment of recurrent high-grade gliomas with GliaSite brachytherapy: a prospective mono-institutional Italian experience. Tumori. 2011;97:614-9.

6. Noda SE, Lautenschlaeger T, Siedow MR, et al Technological advances in radiation oncology for central nervous system tumors. Semin Radiat Oncol. 2009;19:179-86.

7. Savolainen S, Kortesniemi M, Timonen M, et al Boron neutron capture therapy (BNCT) in Finland: technological and physical prospects after 20 years of experiences. Phys Med. 2013;29:23348.

8. Barth RF, Vicente MG, Harling OK, et al. Current status of boron neutron capture therapy of high grade gliomas and recurrent head and neck cancer. Radiat Oncol. 2012;7:146.

9. Al-Saihati I, Naqvi AA. Neutron and gamma ray doses from a ${ }^{252} \mathrm{Cf}$ brachytherapy source in a water phantom. J Radioanal Nucl Chem [internet]. 2012 Set [cited 2012 Nov 28]. Available from: http:// link.springer.com/article/10.1007\%2Fs 10967 012-2172-5\#page-1.

10. Brandão SF, Campos TPR. Análise comparativa da taxa de dose em tumor cerebral através de radioterapia megavoltagem $10 \mathrm{MV}$ e BNCT - Boron Neutron Capture Therapy. [Dissertação]. Belo Horizonte: Universidade Federal de Minas Gerais; 2008.

11. Trindade BM, Campos TPR. Sistema computacional para dosimetria de nêutrons e fótons baseado em métodos estocásticos aplicado a radioterapia e radiologia. Radiol Bras. 2011;44:10916.

12. Trindade BM, Christóvão MT, Trindade DFM, et al. Dosimetria comparativa de braquiterapia de próstata com sementes de I-125 e Pd-103 via SISCODES/MCNP. Radiol Bras. 2012;45:267-72.

13. Binns PJ, Riley KJ, Harling OK, et al. An international dosimetry exchange for boron neutron 
capture therapy. Part I: absorbed dose measurements. Med Phys. 2005;32:3729-36.

14. Riley KJ, Binns PJ, Harling OK, et al. An international dosimetry exchange for BNCT. Part II: computational dosimetry normalizations. Med Phys. 2008;35:5419-25.

15. X-5 Monte Carlo Team. MCNP - A General Monte Carlo N-Particle Transport Code, Version 5 - Volume I: Overview and theory. Los Alamos: Los Alamos National Laboratory; 2003.

16. Sadeghi M, Enferadi M, Shirazi A. External and internal radiation therapy: past and future directions. J Cancer Res Ther. 2010;6:239-48.

17. Amelio D, Lorentini S, Schwarz M, et al. Intensity-modulated radiation therapy in newly diagnosed glioblastoma: a systematic review on clinical and technical issues. Radiother Oncol. 2010; 97:361-9.

18. Cuneo KC, Vredenburgh JJ, Sampson JH, et al. Safety and efficacy of stereotactic radiosurgery and adjuvant bevacizumab in patients with recurrent malignant gliomas. Int J Radiat Oncol Biol Phys. 2012;82:2018-24.
19. Brandão SF, Campos TPR. Brain tumour and in filtrations dosimetry of boron neutron capture therapy combined with ${ }^{252} \mathrm{Cf}$ brachytherapy. Radiat Prot Dosimetry. 2012;149:289-96.

20. Schwarz SB, Thon N, Nikolajek K, et al. Iodine125 brachytherapy for brain tumours - a review. Radiat Oncol. 2012;7:30

21. Liu BL, Cheng JX, Zhang X, et al. Controversies concerning the application of brachytherapy in central nervous system tumors. J Cancer Res Clin Oncol. 2010;136:173-85.

22. Niyazi M, Siefert A, Schwarz SB, et al. Therapeutic options for recurrent malignant gliomas. Radiother Oncol. 2011;98:1-14.

23. Wernicke AG, Sherr DL, Schwartz TH, et al. The role of dose escalation with intracavitary brachytherapy in the treatment of localized CNS malignancies: outcomes and toxicities of a prospective study. Brachytherapy. 2010;9:91-9.

24. Cruickshank GS, Ngoga D, Detta A, et al. A cancer research UK pharmacokinetic study of BPAmannitol in patients with high grade glioma to optimise uptake parameters for clinical trials of
BNCT. Appl Radiat Isot. 2009;67(7-8 Suppl): S31-3.

25. Wittig A, Stecher-Rasmussen F, Hilger RA, et al Sodium mercaptoundecahydro-closo-dodecaborate $(\mathrm{BSH})$, a boron carrier that merits more attention. Appl Radiat Isot. 2011;69:1760-4.

26. Aiyama H, Nakai K, Yamamoto T, et al. A clinical trial protocol for second line treatment of malignant brain tumors with BNCT at University of Tsukuba. Appl Radiat Isot. 2011;69:1819-22.

27. Yamamoto T, Nakai K, Nariai T, et al. The status of Tsukuba BNCT trial: BPA-based boron neutron capture therapy combined with X-ray irradiation. Appl Radiat Isot. 2011;69:1817-8.

28. Nakai K, Yamamoto T, Aiyama H, et al. Boron neutron capture therapy combined with fractionated photon irradiation for glioblastoma: a recursive partitioning analysis of BNCT patients. Appl Radiat Isot. 2011;69:1790-2.

29. Kageji T, Mizobuchi Y, Nagahiro S, et al. Clinical results of boron neutron capture therapy (BNCT) for glioblastoma. Appl Radiat Isot. 2011;69:1823-5. 